\title{
FORMAÇÃO DE PROFESSORES DA EAD PARA USO DAS TIC'S NA REGIÃO AMAZÔNICA: TUTOR PRESENCIAL
}

\author{
J. C. Silva ${ }^{1 *}$, O. Zivieri Neto ${ }^{2}$, A. S. Silva Júnior ${ }^{3}$, G. S. Nascimento ${ }^{4}$ \\ ${ }^{1,3,4}$ Instituto Federal de Rondônia, ${ }^{2}$ Universidade Federal de Rondônia \\ jeferson.cardoso@ifro.edu.br \\ Submetido 08/02/2017 - Aceito 13/04/2017 \\ DOI: $10.15628 /$ holos. 2017.5626
}

\section{RESUMO}

Esta pesquisa teve como objetivo geral verificar a formação dos Tutores Presenciais que atuam na Educação à Distância na região Amazônica. Os colaboradores da pesquisa são docentes dos cursos EAD do IFRO campus Porto Velho Zona Norte, com amostragem total de 29 indivíduos destes apresentados. A coleta de dados se deu a partir da aplicação de um questionário com perguntas fechadas e abertas. Este instrumento foi submetido e posteriormente aprovado pelo comitê de ética em pesquisa, atendendo aos preceitos éticos da resolução $466 / 12$ do Conselho Nacional de Saúde, sob número de parecer: 1.566.512. Após verificação dos dados, percebeu-se que os perfis analisados apontam uma formação majoritariamente de especialistas, o que sugere um conhecimento moderado tendo em vista que nem sempre são especialistas na área em que atuam.

PALAVRAS-CHAVE: Formação de Professores, Educação à Distância, Região Amazônica, Tutor Presencial.

\section{DISTANCE EDUCATION TEACHER TRAINING FOR THE USE OF TIC'S IN THE AMAZON REGION: PRESENT TUTOR}

\begin{abstract}
This research had as general objective to verify the formation of the Presence Tutors that work in Distance Education in the Amazon region. The research collaborators are teachers of the DLE courses of the IFRO campus in Porto Velho Zona Norte, with a total sample of 29 individuals. The data collection was done from the application of a questionnaire with closed and open questions. This instrument was submitted and
\end{abstract}

later approved by the research ethics committee, in compliance with the ethical precepts of Resolution 466/12 of the National Health Council, under the number of opinions: 1.566.512. After verifying the data, it was noticed that the analyzed profiles indicate a formation of specialists, which suggests a moderate knowledge since they are not always specialists in the area in which they work.

KEYWORDS: Teacher Training, Distance Education, Amazon Region, Presential Tutor 


\section{INTRODUÇÃO}

De maneira inicial é indispensável expormos nosso entendimento acerca do que é Educação à Distância, visto que este tema ainda não tem uma uniformidade enquanto conceito. Temos o intuito de divulgar o quão surpreendentes foram as últimas transformações sociais mundiais movidas pelas TIC's - Tecnologias da Informação e Comunicação -, esta ferramenta que está no cerne da EAD. Deste modo, assentimos com (Belloni, 2002, p. 123) entendendo a EAD "como parte de um processo de inovação educacional mais amplo que é a integração das novas tecnologias de informação e comunicação nos processos educacionais".

Atualmente, é cada vez mais crescente a demanda de cursos formais e informais por meio da EAD. O know-how brasileiro nessa modalidade de educação, público e privadas, foram diversos e representaram, nos últimos tempos, a mobilização de grandes contingentes financeiros.

Entretanto, embora progressos extraordinários tenham ocorrido nas últimas décadas, ainda resta uma longa estrada a percorrer para que a EAD consiga ocupar um espaço de evidência no meio educacional, em todos os níveis, vencendo inclusive o preconceito. Diante disto, ressalta-se a importância da formação docente para atuar neste cenário.

Nesta pesquisa, as questões norteadoras foram: qual o nível de escolaridade dos Tutores Presenciais da EAD na Região Amazônica? Em que áreas de conhecimento eles atuam? Tais indagações emergiram no decorrer da disciplina "Educação e Novas Tecnologias" do Mestrado Profissional em Educação Escolar - MEPE/UNIR, ocasião em que o tema formação de professores para atuar com novas tecnologias foi amplamente debatido. Participaram deste estudo: coordenadores de polo, tutores presenciais, tutores a distância e alunos regularmente matriculados no curso Técnico em Finanças desenvolvido pelo IFRO campus Porto Velho Zona Norte na modalidade à distância, dos quais extraímos as informações dos tutores presenciais para tratar nesta pesquisa.

O objetivo geral deste estudo foi verificar a formação dos Tutores Presenciais da EAD na região Amazônica. Os objetivos específicos foram: (i) Investigar a cidade do estado de Rondônia em que atuam; (ii) Descobrir o grau de escolaridade dos tutores; (iii) Analisar em que medida seus cursos de formação tinha relação com a área de atuação; (iv) Identificar se os tutores presenciais apresentam dificuldades no uso das TICs; (v) Averiguar se os tutores apresentam dificuldades em acessar o ambiente virtual de aprendizagem - AVA. Para atingir este fim, aplicamos um questionário aos tutores presenciais, este foi analisado para constatação das hipóteses que elencamos. Esta ferramenta foi submetida ao comitê de ética em pesquisa, sendo aprovada sob parecer de número: 1.566.512.

Os resultados apontam para uma formação predominantemente de especialistas, ainda que não diretamente ligados à sua área de atuação, o que demonstra uma carência de profissionais qualificados para trabalhar na EAD da região Amazônica.

\section{REVISÃO BIBLIOGRÁFICA}

\subsection{Aspectos legais e conceituais da ead}

Em nosso país, a educação escolar configura-se como direito de todos, devendo sua oferta apresentar uma prerrogativa de padrão de qualidade em todas as modalidades de oferta e 
esfera. Os princípios legais para a educação na modalidade à distância foram regulamentados pela Lei de Diretrizes e Bases da Educação Nacional, (LDB) Lei n. 9.394 (1996), que por sua vez, teve suas normas estabelecidas através do Decreto n. 5.622 (2005) com formalização fixada na Portaria Ministerial n. 4.361 (2004).

Entendemos como oportuno, começar distinguindo a expressão Ensino à Distância e Educação à Distância. Concordamos com (Fujita, 2010, pp. 122-123) onde o mesmo cita: "A expressão 'Ensino' sugestivamente nos remete ao paradigma do ensino presencial tradicional, ao papel do professor: considerado o centro das atenções, personagem que ensina, que conduz o aluno ao aprendizado. Particularmente, prefiro a expressão 'Educação' à Distância” em razão de pensarmos que Educação traz em seu cerne uma significação mais abrangente que ensino, na perspectiva de conduzir o estudante ao aprendizado, de modo colaborativo, participativo e significativo.

Por sua vez (Moran, 2005) define EAD como a modalidade de ensino-aprendizagem regulada por tecnologias, em que docentes e discentes permanecem afastados no tempo e/ou espaço, embora possam permanecer interligados, conectados através de tecnologias, a saber: a rede mundial de computadores, o correio tradicional, as emissoras de rádio e de televisão, os aparelhos telefônicos, entre outras coisas similares.

A primeira interpretação feita pela Lei n. 9.394 (1996), acerca do conceito de Educação à Distância foi descrita no Art. 80 da LDB, como "uma forma de ensino que possibilita a autoaprendizagem, com a mediação de recursos didáticos sistematicamente organizados, apresentados em diferentes suportes de informação, utilizados isoladamente ou combinados, e veiculados pelos diversos meios de comunicação". Devido às grandes modificações que esta modalidade de ensino sofre, já em 2005, nova redação foi dada para definir o conceito de EAD: é a modalidade educacional na qual a mediação didático-pedagógica nos processos de ensino e aprendizagem ocorre com a utilização de meios e tecnologias de informação e comunicação, [...] no desenvolvimento de atividades educativas em lugares ou tempos diversos, segundo Decreto n. 5.622 (2005).

Os inúmeros pensamentos sobre EAD podem evidenciar a complexidade da sociedade em interpretar algo em construção. Segundo (Neto, 2012, p. 7) "duas palavras, no entanto, são recorrentes entre pesquisadores e educadores, independentemente da natureza multidimensional da EAD: espaço e tempo". Os atores do desenvolvimento educacional estariam de algum modo, afastados pelo tempo, pelo espaço ou por ambos durante o processo de ensino e aprendizagem. Desta forma, essa modalidade de ensino seria antiga, por exemplo, quando começou a empregar a tecnologia da correspondência impressa ou escrita como didática de ensino, no século XIX.

Nesta parte da pesquisa, buscamos trazer algumas características acerca dos aspectos legais e conceituais de Educação à Distância. Percebemos que o crescente processo de desenvolvimento da EAD tem trazido consigo uma gama de informações construídas à medida que a educação e os processos de ensino aprendizagem se modificam. Tendo em vista a grande demanda por qualificação profissional e tecnológica, urge a necessidade de consolidação tanto da parte conceitual quanto da parte didática da EAD.

\subsection{Limites e possibilidades na formação docente em ead}

A partir da massificação do rádio, da televisão e do cinema, a população passou a contar com uma diversidade singular de agentes de informação. Foi uma fase em que também se estendeu o número de títulos de jornais, livros impressos e revistas. A propagação da informática 
individual estabeleceu novo ritmo à mudança, chegando-se à denominada convergência digital. Segundo (Guimarães, 2012, p. 123) "a cada dia, tecnologias de informação e comunicação mais eficientes e variadas estão à disposição. O mundo passou a contar com um novo fosso de desigualdade, entre os incluídos digitais e os não incluídos", pondera.

Apesar de tanto tempo na educação brasileira, a adoção da Educação à Distância deve vir seguida de concepções e reflexões teóricas e práticas. Para (Vilaça, 2010, p. 90) "em geral, é necessário compreender características, possibilidades, potencialidades e limitações de diferentes formas de ensino, inclusive da Educação à Distância, das tecnologias e dos recursos disponíveis". Contudo, é possível averiguar situações nos quais alguns docentes e discentes exibem entendimentos confusos ou equivocados sobre o que seja EAD, a propósito do julgamento de distância, sobre nomenclaturas utilizadas, entre outras situações.

O sistema educativo vem notando nos últimos anos as consequências da inovação: a transformação das redes de computadores em ambientes virtuais de aprendizagem. Esse novo modelo tem como sugestão o aumento e a democratização da educação. Contudo, este novo ambiente de aprendizagem ainda passa por um período de "aculturação". Essa transformação cultural, ou falta dela, tem causado alguns infortúnios com relação ao uso da EAD e das Tecnologias de Informação e Comunicação - TIC's. Segundo (Almeida, 2008, p.15) "a literatura da área ainda registra altas taxas de evasão de alunos, mostrando que muitos iniciam um curso a distância, mas não conseguem completá-lo".

É inegável que essa nova ordem mundial que vivemos, ocasiona mudanças em toda a sociedade, "afetando diretamente na produção, exploração e socialização dos conhecimentos, abrindo, assim, novos espaços e exigindo novas competências e formações" afirma (Santos, 2015, p.22). Para (Fujita, 2010) estamos passando pela quinta geração da EAD. O autor destaca que atualmente os alicerces continuam sendo as TICS, porém, aproveitando ainda mais de suas especificidades e singularidades.

A comunidade da informação aumenta a relevância do conhecimento e da cultura como elementos primordiais à liberdade e ao progresso da humanidade. Existe uma alteração fundamental em curso, que acomete tanto as relações econômicas quanto sociais. O modo como as informações são elaboradas, conservadas, classificadas, recriadas e distribuídas prejudica a inspeção centralizada desses processos. Em consonância com (Guimarães, 2012, p. 127) "as inovações tecnológicas permitem que se imprima uma velocidade inédita e se alcance um volume praticamente imensurável dessa produção e troca", atesta.

Essa inovação no material pedagógico sucedida nas últimas duas décadas está criando um novo perfil profissional, mas que ainda permanecerá sendo chamado de professor, no entanto, já não se enquadrará no modo anterior. Para (Buarque, 2012, p. 146) menciona que este cenário permanecerá, pois "ele continuará sendo o centro do processo pedagógico. Diante disso, entendemos, então, que o mais importante desafio da educação contemporânea é formar o professor, ou melhor, inventar um novo tipo de educador".

Tendo em vista que o conhecimento está sendo criado e recriado com rapidez e quantidade jamais visto, não é mais factível escapar da imposição de aprender sempre e de forma autônoma. Frequentemente essa necessidade é desvendada através da educação informal, que possui em seu bojo "o respeito aos conhecimentos, às habilidades, às crenças e aos conceitos prévios que influenciam significativamente o que as pessoas percebem sobre o ambiente e o modo como organizam e interpretam essa percepção" confirma (Guimarães, 2012, p. 128).

Sabemos que é papel da educação preparar profissionais partindo da própria evolução do conhecimento mediado pelos instrumentos tecnológicos e de mídia contemporâneo. Contudo, 
independentemente da evolução tecnológica, devemos, como educadores, pensar na formação do indivíduo em sua totalidade, para serem capazes de atuar como pessoas críticas e reflexivas e acima de tudo como cidadãos.

\subsection{Importância da formação docente para uma boa aprendizagem na ead}

É cediça a noção de que domínio de conhecimentos é um dos indicadores de desigualdades sociais. Ela se apresenta como origem caracterizadora de sujeitos e grupos específicos de seres humanos. No entender de (Gatti, 2009, p. 93) "deter certos conhecimentos é poder obter vantagens e facilidades no movente mundo atual. Há conhecimentos que estão na base de ações que podem trazer melhores condições de acesso a bens sociais valorizados [...]".

Nesta comunidade que se estrutura como informático-cibernética o papel da educação é direcionada a prestigiar o controle de determinadas competências a ela associadas e, os que não detêm a expertise para compreender a informação, ou não possui as capacidades que as redes reconhecem, ficam integralmente excluídos. Deste modo, as dinâmicas educacionais, dentro ou fora do contexto escolar, estão em voga e posicionam-se entre promover a mudança ou acentuar a exclusão.

No processo de ensino e aprendizagem apresentado de acordo com o modelo da $E A D, 0$ educador tem papel fundamental. Ele é o mediador da aprendizagem, aquele que instiga, provoca e lança desafios. É ele inclusive quem planeja todo o processo, criando condições para que as operações educacionais sejam provocadoras e estimulantes, de acordo com o nível e perfil dos educandos. Em consonância com (Kenski, Gozzi, \& Jordão, 2014, p. 303) "a formação desse profissional deve lhe garantir condições para estar preparado para o novo, para lidar com as diferenças, para a imprevisibilidade de um ambiente em que os alunos trazem, frequentemente, novos assuntos e novas propostas de discussões".

As instituições de ensino não tem seguido todo o avanço das TICs e verificamos que sua integração na esfera escolar ocorre de modo a não desenvolver seu uso. De acordo com (Bueno \& Gomes, 2011, p. 62) “a experiência empírica tem demonstrado que os 'pacotes' chegam prontos à escola e que os professores não estão preparados para trabalhar no processo ensinoaprendizagem com esses recursos".

A EAD em face de suas especificidades e particularidades enquanto modalidade educativa apresenta preciosas potencialidades de colaborar com a ressignificação da educação escolar e da formação de professores. Consegue propiciar ao educador, possibilidades de estudo, modernização, habilidades, para lançar-se na formação permanente em qualquer lugar e tempo, com métodos diversos tendo como interventor as novas tecnologias de informação e comunicação. A Educação à Distância pode desempenhar um papel alternativo para o docente, outra saída para a cooperação, interlocução, diálogo entre seus pares visando à troca de conhecimentos, de vivências práticas, nos diferentes formatos de ambientes para ensinar e aprender, conforme ponderação de (Aretio, 2002).

A dificuldade que circunda a sistematização e a concretização de cursos e programas de aprendizagem na modalidade à distância para formar docentes aparece como um dos desafios. Ainda são remotas as práticas nesta área e modalidade disponíveis no Brasil. Isso nos leva a inferir que a instalação de cursos EAD para a formação de educadores vem vivendo um momento de experimentação em nosso país. Tais programas necessitam de estudos, análises visando à potencialização de suas capacidades e de novos encaminhamentos. Desta forma, é importante entender a EAD, analisar suas várias vertentes, a infraestrutura tecnológica e gerencial, a administração de recursos, "bem como o sistema de tutoria, a didática, a metodologia, os 
procedimentos de ensino- aprendizagem, de avaliação, a prática do formador e demais componentes dos programas a distância" assegura (Ferreira, 2009, p. 2).

\section{METODOLOGIA}

\subsection{Instrumentos metodológicos e tipo de pesquisa}

Esta pesquisa é parte de uma pesquisa-ação apresentada ao Mestrado Profissional em Educação Escolar - MEPE/UNIR (turma 2015/2), com o seguinte tema: SAAS - sistema de acompanhamento e avaliação de cursos ead: o caso do instituto federal de educação, ciência e tecnologia de Rondônia - IFRO. O questionário original aplicado aos tutores presenciais continha doze (12) questões abertas e fechadas, das quais extraímos quatro (4) para analisar nesta pesquisa.

O SAAS tem a perspectiva de levantar indicadores de qualidade para servir de norte para os gestores dos cursos EAD. A metodologia de acompanhamento e avaliação utiliza como base o Sistema Nacional de Avaliação do Ensino Superior - SINAES. O resultado fundamental aguardado é a expectativa de proporcionar subsídios à coordenação geral da Rede e-Tec Brasil para o controle dos assuntos envolvendo políticas e empenho de recursos técnicos e financeiros, isto é, as coordenações institucionais, gestores gerais do e-Tec e coordenadores de cursos, para suscitar ações de controle e avanço contínuo no processo.

No entender de (Gil, 2009, p. 121) o questionário é "[...] um conjunto de questões que são submetidas a pessoas com propósito de obter informações sobre conhecimentos, crenças, sentimentos, valores, interesses, expectativas, aspirações, temores, comportamento [...]". Depois de elaborado, o questionário passou por uma fase denominada por (Richardson, 2012, p. 202) de pré-teste "refere-se à aplicação prévia do questionário a um grupo que apresente as mesmas características da população incluída na pesquisa. Tem por objetivo revisar e direcionar aspectos da investigação".

\subsection{Participantes da pesquisa}

Por se tratar de parte de Dissertação, esta pesquisa conta com os dados da participação de vinte e nove (29) tutores presenciais, de diversos polos do IFRO. A população da Dissertação foi composta por quatro mil, duzentos e quarenta e dois (4242) sujeitos. A amostragem foi composta por novecentos e seis colaboradores (906), ou seja, do ponto de vista do nível de confiança e erro amostral, a fonte dos dados aqui apresentados tem um índice de confiança e amostragem acima da média. Portanto, a amostragem aparentemente baixa de tutores presenciais justifica-se em virtude da fragmentação dos dados totais do estudo.

Para a aplicação do questionário, aproveitamos a ocasião de um evento sobre EAD em Porto Velho para atingir o máximo de tutores possíveis, neste caso vinte e nove (29) indivíduos. A possibilidade de abarcar diversas regiões remotas e de viabilizar a educação para uma parte da população que não teria acesso à escola, é que torna o ensino na modalidade EAD tão inclusivo. Apresentamos a Figura 1 com o mapa dos polos EAD e campi do IFRO para dar uma visão geral da atuação no estado de Rondônia. 


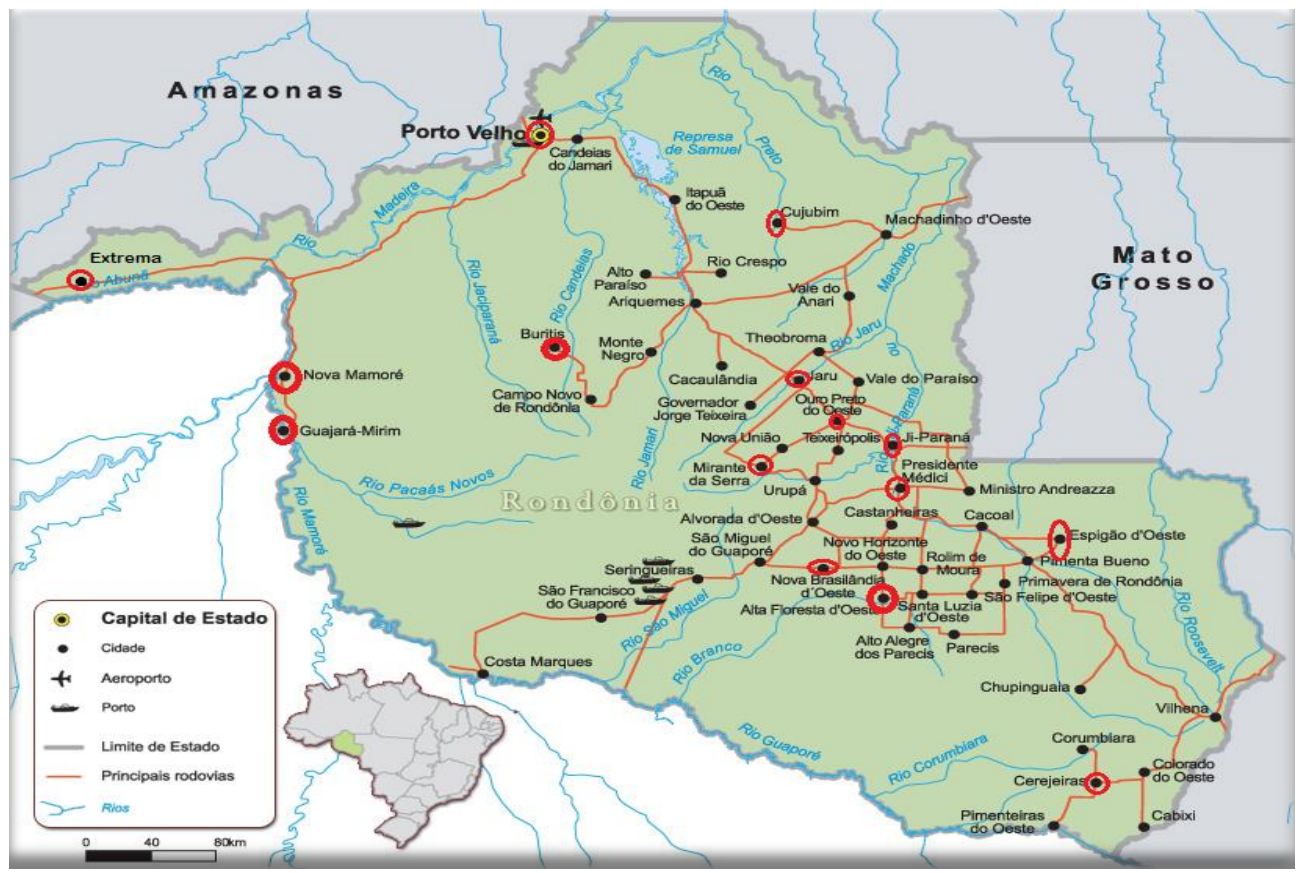

Figura 1: Mapa dos campi do IFRO (http://www.guiageo.com/rondonia.htm), 2016.

Os campi do IFRO estão assim distribuídos: sendo (2) dois em Porto Velho, um em Ariquemes, Jaru, Guajará-Mirim, Ji-Paraná, Cacoal, Vilhena e Colorado d'Oeste. Os que estão em vermelho (exceto Porto Velho), são os polos EAD que, normalmente ficam situados em escolas municipais. As cidades que têm polos EAD do IFRO são: Extrema, Nova Mamoré, Buritis, Cujubim, Machadinho d'Oeste, Jaru, Ouro Preto d'Oeste, Mirante da Serra, Costa Marques, São Francisco do Guaporé, São Miguel do Guaporé, Nova Brasilândia d'Oeste, Alta Floresta d'Oeste, Presidente Médici, Espigão d'Oeste e Cerejeiras.

\section{RESULTADOS E DISCUSSÃO}

A Rede Escola Técnica Aberta do Brasil - Rede e-Tec-, para o qual o SAAS foi elaborado e está sendo utilizado, tem um alcance atual de 20 Estados Brasileiros, proporcionando a oferta de 48 cursos técnicos profissionalizantes, acolhendo em torno de 75 mil estudantes em 542 polos no ano de 2011 (Cislaghi, Nassar, \& Wilges, 2010).

Entendemos como oportuno, esclarecer alguns aspectos acerca da contratação e atuação dos tutores presenciais ${ }^{1}$. No tocante aos requisitos para contratação: a) possuir formação de nível médio ou nível superior, ambos com experiência mínima comprovada de 1 (um) ano na docência; b) não ser recebedor de qualquer bolsa custeada pelos recursos Governamentais; c) ser residente domiciliado na cidade do Polo de Apoio Presencial que pretende se inscrever; d) ter disponibilidade para cumprir 20 (vinte) horas semanais no Polo de apoio presencial; e) caso já tenha sido bolsista do Programa e-Tec no IFRO, o candidato deverá, obrigatoriamente, apresentar o NADA CONSTA dos relatórios das atividades exercidas do período de exercício da função; f) Não estar exercendo atividade como tutor presencial e a distância. Em relação a atuação, o tutor presencial "tem como função auxiliar o coordenador de polo no

\footnotetext{
${ }^{1}$ Disponível em: < file:///C:/Users/Jeferson/Downloads/Edital-tutor-presencial_2016-1_final.pdf> Acesso em: 10 abr. 2017.
} 
desenvolvimento do curso, na interação com o estudante, através de diversas mídias". Outras atribuições do tutor presencial são²:

a) realizar as atividades típicas de tutoria presencial, tais como: permanecer em sala e participar do chat durante a teleaula, registrar e lançar presença no Ambiente Virtual de Aprendizagem (AVA), lançar gabaritos de notas, dentre outras, cumprindo os prazos estabelecidos; b) participar das atividades referentes ao curso e de preparação profissional para o exercício da tutoria e dos processos de avaliação; c) participar dos momentos de formação e reuniões para tutores via videoconferência proporcionados pelo IFRO; d) assistir aos alunos nas atividades desenvolvidas no polo; e) orientar e estimular os estudos, favorecendo a interação entre professor formador e alunos, entre tutor a distância e alunos, entre alunos e o coordenador de polo; f) coordenar as atividades presenciais; g) auxiliar na elaboração dos relatórios necessários ao bom desenvolvimento do processo de ensino aprendizagem; h) acompanhar os relatórios de desempenho dos alunos nas atividades desenvolvidas; i) estar à disposição dos estudantes, nos horários de plantão, conforme estabelecido pela coordenação de Polo; j) apoiar operacionalmente a coordenação do curso nas atividades presenciais nos polos; k) orientar os alunos quanto ao uso do Ambiente Virtual de Aprendizagem - AVA; I) participar dos momentos das avaliações presenciais (regular, segunda chamada, recuperação e exame final) e das reuniões com o coordenador de polo; m) acompanhar individualmente os alunos na aula presencial e no lançamento/acompanhamento de atividades no AVA;

A primeira questão que analisamos utilizando o questionário foi em relação ao polo de atuação dos tutores. Conforme foi visto na Figura 1, a cobertura dos cursos na modalidade à distância do IFRO perpassa todo o estado. Apresentaremos no figura 2 todas as informações detalhadas. Percebe-se analisando a figura 2 que dos vinte e cinco (25) polos e campi integrantes da EAD do IFRO, treze (13) estão representados por seus tutores. Isto nos dá um percentual de $52 \%$ de participação, de tal modo que para cada região do estado teremos um representante. Eles ficaram assim distribuídos: quatro (4) em Alta Floresta, dois (2) em Buritis, dois (2) em Cerejeiras, três (3) em Cujubim, dois (2) em Espigão do Oeste, dois (2) em Extrema, um (1) em Jaru, Guajará Mirim, Mirante da Serra e Ouro Preto do Oeste, quatro (4) em Ji-paraná, três (3) em Nova Mamoré e Nova Brasilândia.

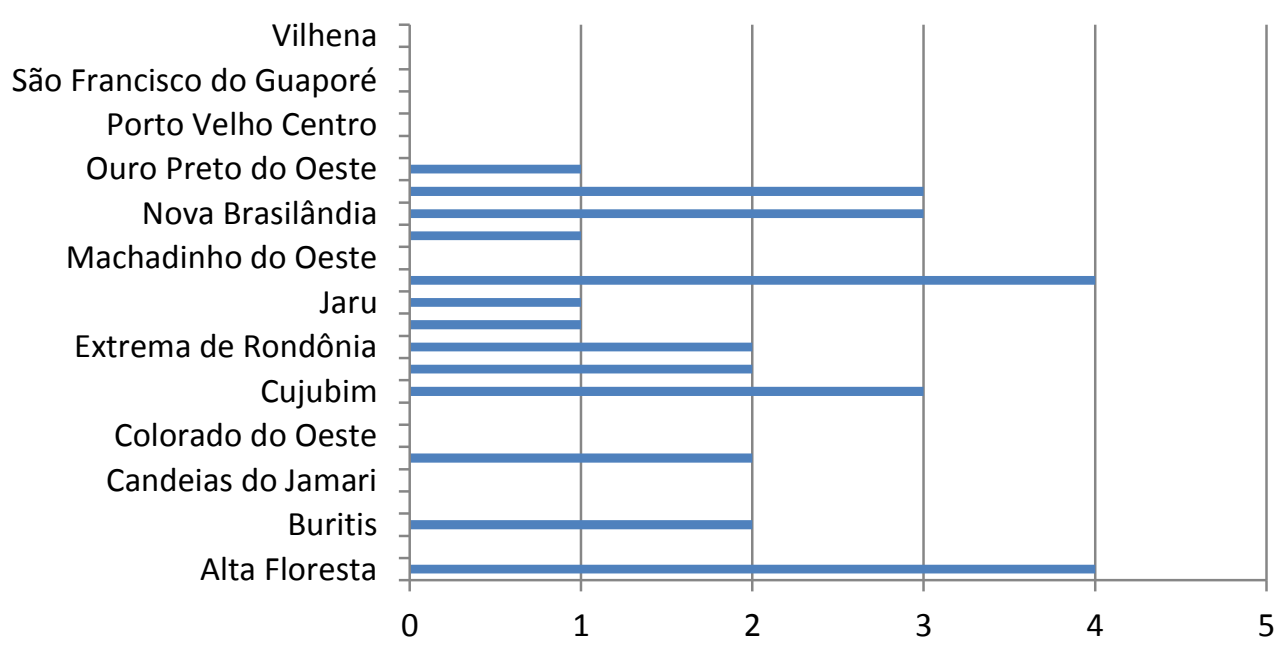

Figura 2: Polo de atuação dos tutores presenciais.

\footnotetext{
${ }^{2}$ Idem nota anterior.
} 
A segunda questão examinada foi o grau de escolaridade dos tutores presenciais. A figura 3 apresenta os resultados.

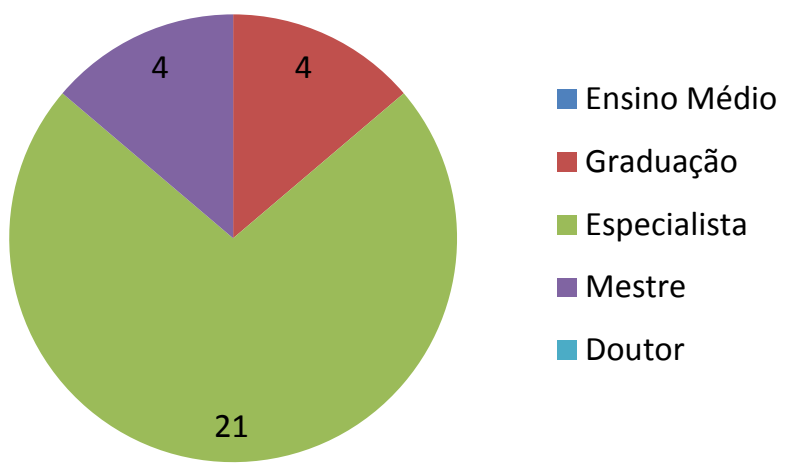

Figura 3: Grau de escolaridade dos tutores presenciais.

Os tutores presenciais foram assim classificados: (4) graduados, (21) especialistas e (4) mestres, ou seja, são predominantemente especialistas. Segundo (Belloni, 2002, p. 139) "nas sociedades contemporâneas, 'do conhecimento' ou 'da informação', a formação inicial torna-se rapidamente insuficiente e as tendências mais fortes apontam para uma 'educação ao longo da vida' [...]". Percebemos que os tutores estão seguindo a ideia do autor, pois maioria absoluta deles possui ao menos uma especialização lato sensu.

Contudo, segundo (Bueno \& Gomes, 2011, p. 60), a EAD é utilizada para apressar a formação de professores [...] "cursos superiores à distância [...] para a aceleração dessa formação e para a não realização de uma formação docente conforme prescrita na LDB, que articule ensino, pesquisa e extensão, que relacione a teoria e prática e que promova uma formação crítica".

Considerando a LDB no seu artigo 3 inciso IX e artigo 4 inciso IX, existe uma previsão de assegurar padrões de qualidade, bem como é dever do estado em garantir esses padrões mínimos. Entretanto, existem diversos cursos EAD que empregam um docente para lecionar atividades para uma imensa quantia de educandos, que são acompanhados por tutores que não detém conhecimento específico para difundir a aprendizagem dos conteúdos propostos. É evidente que tal colocação não se consagra a todos as formações EAD oferecidas no país, contudo, muitos enfrentam esse tipo de barreira, que provoca a fragilidade na ação do professor.

Outra vez, evidenciamos a sugestão de formação continuada tal qual o previsto no Plano Nacional de Educação - PNE (2014) “[...] fomentar a formação continuada de professores e professoras para o atendimento educacional especializado nas escolas urbanas, do campo, indígenas e de comunidades quilombolas".

Ainda no tocante a importância da formação contínua do professor/tutor, (Ferreira, 2009, p. 25) ressalta que, em virtude de a EAD estar despontando atualmente pelo uso intenso de novas tecnologias, vários processos de formação que estão acontecendo, encontra-se ainda em fase experimental, "[...] exigindo acompanhamento, investigações e adaptações em relação à sua estruturação e desenvolvimento, para que possa efetivamente representar suas potencialidades como modalidade educativa na formação de professores".

Assentimos com (Kenski, 1998, p. 60) no sentido de que "não existe mais a possibilidade de considerar-se alguém totalmente formado, independentemente do grau de escolarização alcançado". 
Outro ponto abordado foi se os tutores possuíam cursos de formação para trabalhar na educação à distância. A figura 4 apresenta estas informações.

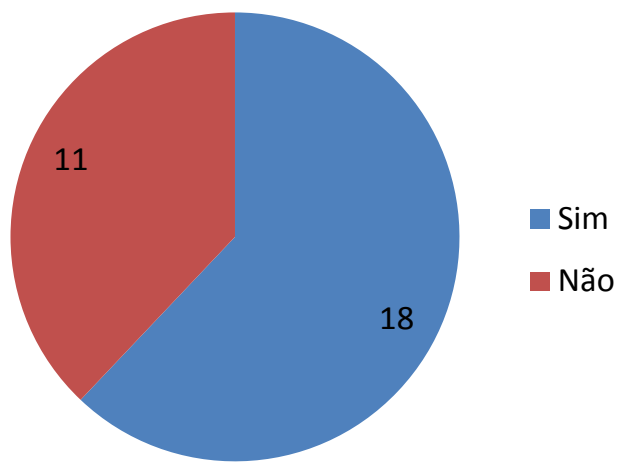

Figura 4: Curso de formação EAD.

Depreende do Gráfico 3 que dos vinte e nove tutores (29) somente dezoito (18) tem formação específica para atuar na EAD. Onze (11) assinalaram não ter formação adequada. Identificamos que alguns cursos apresentados pelos tutores não mencionavam a instituição formadora, o que nos leva a deduzir que possam não ter concluído o curso e até mesmo que este não exista. Os cursos de formação mencionados são: Técnico em Segurança do Trabalho, História, Metodologia no ensino de Linguagens, Cursos do Sebrae, Pós graduação em Coordenação de Polo, Proinfo, entre outros (estes são alguns exemplos descritos pelos tutores). Para (Vilaça, 2010, p. 96) "é necessário que os professores sejam devidamente preparados em termos pedagógicos e tecnológicos para a EAD, compreendendo suas possibilidades, características e potencialidades". Além da formação contínua, já proposta por (Belloni, 2002), é importante que os educadores estejam preparados para o uso da tecnologia na aprendizagem.

Os cursos promovidos pelo IFRO na EAD são das seguintes áreas de conhecimento: Gestão e Negócios e, Informação e Comunicação. Comparando tais áreas com as informadas pelos tutores com relação à própria formação, percebemos que poucos tutores apresentam formação ligada aos cursos que o IFRO oferece na EAD, a saber: Técnico em Informática para Internet, Técnico em Finanças e Profuncionário (Técnico em Alimentação Escolar, Técnico em Infraestrutura, Técnico em Multimeios Didáticos e Técnico em Secretaria Escolar).

A Lei n. 9.394/96 em seu artigo 87 ressalta a necessidade de majorar o nível de formação dos profissionais da educação, estabelecendo que "cada Município e, supletivamente, o Estado e a União, deverá [...] realizar programas de capacitação para todos os professores em exercício, utilizando também, para isto, os recursos da Educação à Distância".

Entretanto, o Art. 1으, VIII, da Resolução n. 18 (2010) do Ministério da Educação cita o seguinte: "tutor: selecionado pelas IPE vinculadas ao Sistema e-Tec Brasil para o exercício das atividades típicas de tutoria, sendo exigida formação de nível médio e experiência mínima de 1 (um) ano no magistério". Neste ponto, evidenciamos uma dispensa de formação em nível superior para atuar na tutoria presencial, exigindo-se somente experiência prévia na docência, 0 que não encontra respaldo no PNE em relação às metas e estratégias lá definidas. 


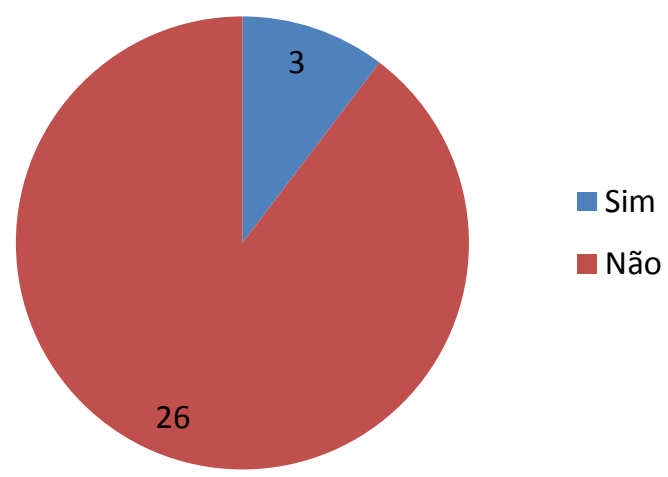

Figura 5: Dificuldades para acessar o AVA.

Na figura 5, apresentamos as informações referentes à dificuldade dos tutores em acessar o ambiente virtual de aprendizagem. Percebemos que a representatividade de tutores respondendo não ter dificuldades em acessar o AVA ser de vinte e seis (26) e apenas três (3) assinalar ter dificuldades. Concordamos com (Almeida, 2005, p. 43) por entender que "caso o professor não conheça as características, as potencialidades e as limitações das tecnologias e mídias, ele poderá desperdiçar a oportunidade de favorecer um desenvolvimento mais poderoso do aluno".

De acordo com a Resolução n. 18 (2010), em seu anexo I, item 3.7, o tutor tem os seguintes deveres: "[...] estar presente na instituição de ensino para atividades online; acessar regularmente o AVA para acompanhamento dos cursistas [...] (grifo nosso)". Desta forma, percebe-se um distanciamento entre o prescrito na lei com a realidade encontrada. De fato, o design do AVA é bem acessível a todos, contudo, concordamos com (Bueno \& Gomes, 2011, p. 63), pois em relação às tecnologias "[...] é necessário que o professor tenha condições de usá-las e isso significa, entre outros aspectos, domínio das ferramentas [...] não basta disponibilizá-las para que os problemas sejam resolvidos".

Assentimos com (Neves, 2005, p. 140) em virtude de entendermos que em cursos na modalidade à distância "[...] eleva-se o nível de exigência dos recursos humanos envolvidos: além de professores-especialistas nas disciplinas, deve-se contar com tutores, avaliadores, especialistas em comunicação e no suporte de informação [...]". De acordo com (Ferreira, 2009, p. 24) "[...] tanto o papel do professor como o do aluno na modalidade de EAD, não estão prontos, precisam ser criados, aperfeiçoados continuamente nesta nova área de prática educativa, o que não pode ser feito de um dia para o outro".

Por se tratar de um curso EAD e, deste modo, o AVA ser um ponto de encontro para esclarecer dúvidas, analisar material, participar de chats, entre outras coisas, é que se torna imprescindível o acesso do aluno. Para (Neves, 2005, p. 140) "é engano considerar que programas a distância podem dispensar o trabalho e a mediação do professor. Nos cursos à distância, os professores veem suas funções se expandirem". Sob este aspecto que enfatizamos a importância do papel do tutor para motivar o aluno a acessar o ambiente virtual.

Para (Moran, 1994, p. 2) "[...] o papel do professor vem sendo redimensionado e cada vez mais ele se torna um supervisor, um animador, um incentivador dos alunos na instigante aventura do conhecimento". Inúmeros estudiosos como (Moran, 1994, 2005; Ferreira, 2009; Garcia Aretio, 2002) entre outros, apontam que o tutor é figura decisiva na Educação à Distância. Cabe a ele auxiliar os alunos para o êxito em um curso EAD e para favorecer o aprendizado do 
estudante nesta modalidade. Deste modo, o educador deve entre outras coisas, estimular e motivar a todo tempo o estudante, no sentido de aumentar sua autoconfiança e participação, de tal forma que possa influenciar positivamente na formação e pleno exercício da cidadania.

\section{CONCLUSÃO}

Os argumentos aqui apresentados são formulados com base nos questionamentos apontados no decorrer da pesquisa, agregados às informações coletadas com a aplicação do questionário e pautados nos estudiosos referendados na pesquisa. $O$ objetivo central que norteou este trabalho foi verificar a formação dos tutores presenciais da educação à distância na região amazônica. Aplicamos um questionário aos tutores presencias, com o intuito de atingir nosso objetivo. Deste modo, pudemos posteriormente tratar e analisar as informações coletadas.

Em resposta aos nossos questionamentos, verificamos que os cursos EAD do IFRO têm uma grande abrangência e importância dentro do estado de Rondônia, tamanho é o seu alcance. Participaram deste estudo tutores representantes de ambas as mesorregiões do estado.

Com relação ao grau de escolaridade percebemos uma prevalência de especialistas atuando na área, ainda que com formação em áreas não condizentes com sua prática. Apesar de não ser exigida uma formação em nível superior para atuar como tutor presencial, apenas experiência mínima de um (1) ano de magistério, o posicionamento dos autores aqui apresentados não coaduna com o que é posto no Art. 10, VIII, da Resolução n. 18 (2010). É importante aqui ressaltar que, para o processo de seleção dos tutores presenciais é instituído uma Comissão de Elaboração e Análise de todo o processo por meio de portaria emanada pelo Diretor Geral do campus, neste caso, todos os selecionados serão beneficiários de uma retribuição pecuniária (Bolsa Formação) do Programa Rede e-Tec enquanto tiverem vínculo com a instituição.

Identificamos que maioria absoluta dos tutores não apresentavam dificuldades em acessar o AVA, contudo a literatura aponta para um aprimoramento constante em relação ao uso das tecnologias. Por fim, concluímos baseado no que até agora expomos, que existe uma formação docente precária, insuficiente e incapaz de atender às novas exigências da sociedade, contudo, sugerimos que para atuação na área de tutor presencial seja exigida formação mínima de especialista na área. Entretanto, somos sabedores de que os dados aqui apresentados não esgotam a temática, deste modo, recomendamos que novos estudos com este enfoque sejam desenvolvidos.

\section{REFERÊNCIAS}

Almeida, M. E. B. (2005). Prática e formação de professores na integração de mídias. Prática pedagógica e formação de professores com projetos: articulação entre conhecimentos, tecnologias e mídias. In: ALMEIDA, M.E.B. \& Moran, J. M. (Orgs.). Integração das Tecnologias na Educação. Brasília, DF: Ministério da Educação.

Almeida, O. C. S. (2008). Evasão em curso a distância: análise dos motivos de desistência. Dissertação de Mestrado, UnB, Brasília, DF, Brasil.

Belloni, M. L. (2002). Ensaio sobre a Educação à Distância no Brasil. Educação e sociedade. Scielo Brasil, Vol. 23 (n.78), 117-142. Recuperado em 05 Setembro, 2016, de http://www.scielo.br/scielo.php?pid=S0101-

$73302002000200008 \&$ script=sci_arttext\&tlng=pt 
Buarque, C. (2012). Formação e invenção do professor no século XXI. In: Litto, F. M. \& Formiga, M. (Orgs.). Educação à Distância: o estado da arte (2. ed.). São Paulo: Pearson Education.

Bueno, J. L. P \& Gomes, M. A. O. (2011). Uma análise histórico-crítica da formação de professores com tecnologias de informação e comunicação. Revista Cocar, v. 5 (n. 10), p. 53-64. Recuperado em Janeiro, 2016 de http://paginas.uepa.br/seer/index.php/cocar/article/download/196/170

Cislaghi, R., Nassar, S. M., \& Wilges, B. (2010). Sistema de avaliação e apoio à qualidade do ensino a distância. Recuperado em 30 Julho, 2015 de http://moodle.saas.etec.ufsc.br/saas/moodle

Decreto 5.622, de 19 de dezembro de 2005. Regulamenta o artigo 80 da Lei no 9.394, de 20 de dezembro de 1996, que estabelece as diretrizes e bases da educação nacional. Brasília, DF. Recuperado em 25 novembro, 2016 de http://www.planalto.gov.br/ccivil_03/_Ato20042006/2005/Decreto/ D5622.htm

Ferreira, Z. M. (2009). Prática pedagógica do professor-tutor em Educação à Distância no curso Veredas - Formação Superior de Professores. Tese de Doutorado em Educação, Universidade de São Paulo, São Paulo, SP, Brasil.

Fujita, O. M. (2010). Educação à Distância, currículo e competência: uma proposta de formação on-line para a gestão empresarial. Tese de Doutorado em Educação, Universidade de São Paulo, São Paulo, SP, Brasil.

Garcia Aretio, L. (2002). Resistencias, cambio y buenas prácticas en la nueva educación a distancia. Revista Iberoamericana de Educación a Distancia, Vol. 5 (n. 2), pp. 9 - 36. Recuperado em 24 Novembro, 2015 de www.uned.es/catedraunesco-ead

Gatti, B. A. (2009). Formação de professores: condições e problemas atuais. Revista Brasileira de Formação de Professores, Vol. 1, (n. 1), pp- 90-102.

GIL, A.C. (2009). Métodos e técnicas de pesquisa social (6a ed.). São Paulo: Atlas.

Guimarães, L. S. R. (2012). O aluno e a sala de aula virtual. In: LITTO, F. M. \& Formiga, M. (Orgs.). Educação à Distância: o estado da arte (2. ed.). São Paulo: Pearson Education.

Kenski, V. M. (1998). Novas tecnologias: O redimensionamento do espaço e do tempo e os impactos no trabalho docente. Revista Brasileira de Educação, São Paulo, (n. 8) pp. 58-71.

Kenski, V. M.; Gozzi, M. P.; \& Jordão, T. C. (2014). A Experiência de ensinar e aprender em ambientes virtuais abertos. Recursos Educacionais Abertos \& Redes Sociais. São Luís, Abeu ( 2. ed.), pp. 303-313.

Lei no 13.005, de 25 de junho de 2014. Aprova o Plano Nacional de Educação - PNE e dá outras providências. Brasília, DF. Recuperado em 06 Junho, 2016 de http://www.planalto.gov.br/ccivil_03/_ato2011-2014/2014/lei/l13005.htm

Lei no 9.394, de 20 de dezembro de 1996. Estabelece as diretrizes e bases da educação nacional. Brasília, DF. Recuperado em 08 Setembro, 2016 de http://www.planalto.gov.br/ccivil_03/leis/19394.htm

Moran, J. M. (1994). O que é Educação à Distância. Centro de Educação à Distância, Rio de Janeiro, SENAI, ano 1, (n. 5), pp. 1-3. Recuperado em 03 Fevereiro, 2016 de http://www2.eca.usp.br/moran/wp-content/uploads/2013/12/dist.pdf

Moran, J. M. (2005). O que é um bom curso à distância? In: ALMEIDA, M.E.B. \& Moran, J. M. (Orgs.). Integração das Tecnologias na Educação. Brasília, DF: Ministério da Educação.

Neto, J. A. M. (2012). Superando barreiras naturais: a EAD na região amazônica. In: LITTO, F. M. \& Formiga, M. (Orgs.). Educação à Distância: o estado da arte (2. ed.). São Paulo: Pearson Education.

Neves, C. M. C.(2005). A Educação à Distância e a formação de professores. In: ALMEIDA, M.E.B. \& Moran, J. M. (Orgs.). Integração das Tecnologias na Educação. Brasília, DF: Ministério da 


\section{Educação.}

Resolução no 18, de 16 de junho de 2010. Altera a Resolução CD/FNDE no 36, de 13 de julho de 2009, que estabelece orientações e diretrizes para concessão e pagamento de bolsas de estudo e pesquisa no âmbito do Sistema Escola Aberta do Brasil (Programa e-Tec Brasil). Brasília, DF. Recuperado em 25 Janeiro, 2016 de https://www.fnde.gov.br

Richardson, R.J. (2012). Pesquisa Social: Métodos e Técnicas (3. ed.). São Paulo: Atlas.

Santos, M. F. dos. (2015). A construção da autonomia do sujeito aprendiz no contexto da EAD. Revista Brasileira de Aprendizagem aberta e à Distância, São Paulo, v. 14, pp. 21-35.

Vilaça, M. L. C. (2010). Educação à Distância: conceitos, termos e um pouco de história. Revista Magistro. Programa de Pós-Graduação em Letras e Ciências, Unigranrio, Rio de Janeiro, Vol.2, (no 1). Recuperado em 24 Novembro, 2015 de http://publicacoes.unigranrio.edu.br/index.php/magistro/article/view/1197/699 